Article

\title{
Salidroside Attenuates Hydrogen Peroxide-Induced Cell Damage Through a cAMP-Dependent Pathway
}

Shuang Guan ${ }^{1}$, Wei Wang ${ }^{1, \dagger}$, Jing Lu ${ }^{1,2, \dagger}$, Wenhui Qian ${ }^{2}$, Guoren Huang ${ }^{2}$, Xuming Deng ${ }^{1, *}$ and Xuelin Wang ${ }^{1, *}$

1 Institute of Zoonoses, College of Animal Science and Veterinary Medicine, Jilin University, Changchun, Jilin 130062, China; E-Mails: gshuang1973@126.com. (S.G.); wangwei@jluhp.edu.cn (W.W.)

2 Laboratory of Nutrition and Function Food, Jilin University, Changchun, Jilin 130062, China; E-Mail: xlujing1@yahoo.com.cn (J.L.)

$\dagger$ These authors contributed equally to this work.

* Authors to whom correspondence should be addressed; E-Mails: xumingdeng@yahoo.com.cn (X.D.); wxlwqx@sohu.com (X.W.); Tel.: +86-431-8783-6161; Fax: +86-431-8783-6160.

Received: 25 March 2011; in revised form: 8 April 2011 / Accepted: 8 April 2011 /

Published: 19 April 2011

\begin{abstract}
Salidroside, a major component of Rhodiola rosea L., has shown various pharmacological functions, including antioxidant effects, but the signal transduction pathway of its antioxidant effects is not very clear. In this study, we found that salidroside could attenuate hydrogen peroxide $\left(\mathrm{H}_{2} \mathrm{O}_{2}\right)$-induced $\mathrm{HL}-7702$ cell damage, inhibit $\mathrm{H}_{2} \mathrm{O}_{2}$-induced cytosolic free $\mathrm{Ca}^{2+}\left(\left[\mathrm{Ca}^{2+}\right]\right.$ i) elevation, scavenge reactive oxygen species (ROS) and increase 3'-5' -cyclic adenosine monophosphate (cAMP) level in a dose-dependent manner, but it couldn't influence 3'-5'-cyclic guanosine monophosphate (cGMP) levels. Therefore, these results indicated that the antioxidant effects of salidroside were associated with down-regulation of $\left[\mathrm{Ca}^{2+}\right] \mathrm{i}$, ROS occur via a cAMP-dependent pathway.
\end{abstract}

Keywords: salidroside; antioxidant; AMP; cGMP; $\left[\mathrm{Ca}^{2+}\right] \mathrm{i}$; ROS 


\section{Introduction}

Rhodiola rosea $L$. has been widely used for a long time in Traditional Chinese Medicine. Salidroside ( $p$-hydroxyphenethyl- $\beta$-D-glucoside, $\mathrm{C}_{14} \mathrm{H}_{20} \mathrm{O}_{7}, 300.30$ ), as shown in Figure 1 , has been identified as the most potent ingredient in this medicinal plant [1]. Some studies have shown that salidroside possesses various pharmacological functions, including anti-aging [2], anti-cancer [3-5], anti-viral [6-8], anti-inflammatory [9], neuroprotective [10,11], hepatoprotective [9], cardiomyocytes protective [12,13], anti-diabetic [14] and antioxidant effects $[15,16]$.

Oxidative damage, mediated by reactive oxygen species (ROS) has been thought as a major cause of atherosclerosis, cancer, liver disorder and the aging process [17]. In previously studies, people found that the antioxidant mechanism included $\left[\mathrm{Ca}^{2+}\right] \mathrm{i}$ and $\mathrm{NO}$ signaling pathways $[18,19]$, thus it might involve the 3'-5'-cyclic adenosine monophosphate (cAMP)/3'-5'-cyclic guanosine monophosphate (cGMP)-dependent signaling pathway. To the best of our knowledge, no one has investigated the role of cAMP/cGMP in the antioxidant effects of salidroside, so the objective of the present paper was to examine the effects of salidroside on $\mathrm{H}_{2} \mathrm{O}_{2}$-induced oxidative damage, cAMP, cGMP; $\left[\mathrm{Ca}^{2+}\right] \mathrm{i}$ and ROS levels in HL-7702 cells to determine whether the cAMP/cGMP pathway participate in the antioxidant effects of salidroside. Our results would be benefitial for development of salidroside as a potential agent for treatment of oxidative stress-related diseases.

Figure 1. Structure of salidroside.

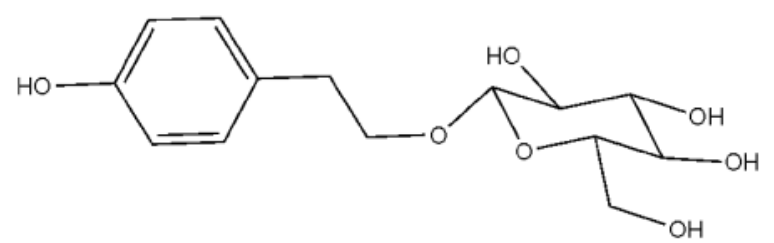

\section{Results and Discussion}

\subsection{Protective Effect of Salidroside on $\mathrm{H}_{2} \mathrm{O}_{2}$-Induced Cell Damage}

The protective effect of salidroside on $\mathrm{H}_{2} \mathrm{O}_{2}$-induced cell damage as determined by the MTT assay is shown in Figure 2. Incubating with $\mathrm{H}_{2} \mathrm{O}_{2}(0.5 \mathrm{mM})$ for $100 \mathrm{~min}$ induced significant cell damage. Pretreatment with salidroside $(0.03,0.05,0.1 \mu \mathrm{g} / \mathrm{mL})$ could attenuate $\mathrm{H}_{2} \mathrm{O}_{2}$-induced cell damage in a dose-dependent manner $(p<0.05)$, though it couldn't restore the damaged cells totally. Data are expressed as mean \pm S.D. $(n=4) .{ }^{\#} p<0.05$ and ${ }^{\# \#} p<0.01$ compared with Control.

\subsection{Salidroside Inhibited $\mathrm{H}_{2} \mathrm{O}_{2}$-Induced $\left[\mathrm{Ca}^{2+}\right]$ i Elevation}

We examined the effect of salidroside on $\left[\mathrm{Ca}^{2+}\right]$ i. We found that incubating with $\mathrm{H}_{2} \mathrm{O}_{2}(0.5 \mathrm{mM})$ for 100 min induced a significant $\left[\mathrm{Ca}^{2+}\right]$ i elevation, while pre-incubation with salidroside dose dependently suppressed the elevation of $\left[\mathrm{Ca}^{2+}\right] \mathrm{i}$ (Figure 3 ). Data are expressed as mean \pm S.D. $(\mathrm{n}=4) .{ }^{*} \mathrm{p}<0.05$ and $* * \mathrm{p}<0.01$ compared with Control; $\# \mathrm{p}<0.05$ and \#\# $\mathrm{p}<0.01$ compared with $\mathrm{H}_{2} \mathrm{O}_{2}$ group. 
Figure 2. Protective effect of salidroside on $\mathrm{H}_{2} \mathrm{O}_{2}$-induced cell damage. Cells were treated with salidroside followed by $\mathrm{H}_{2} \mathrm{O}_{2}$ as described in 2.2 and cell viability was determined by MTT assay.

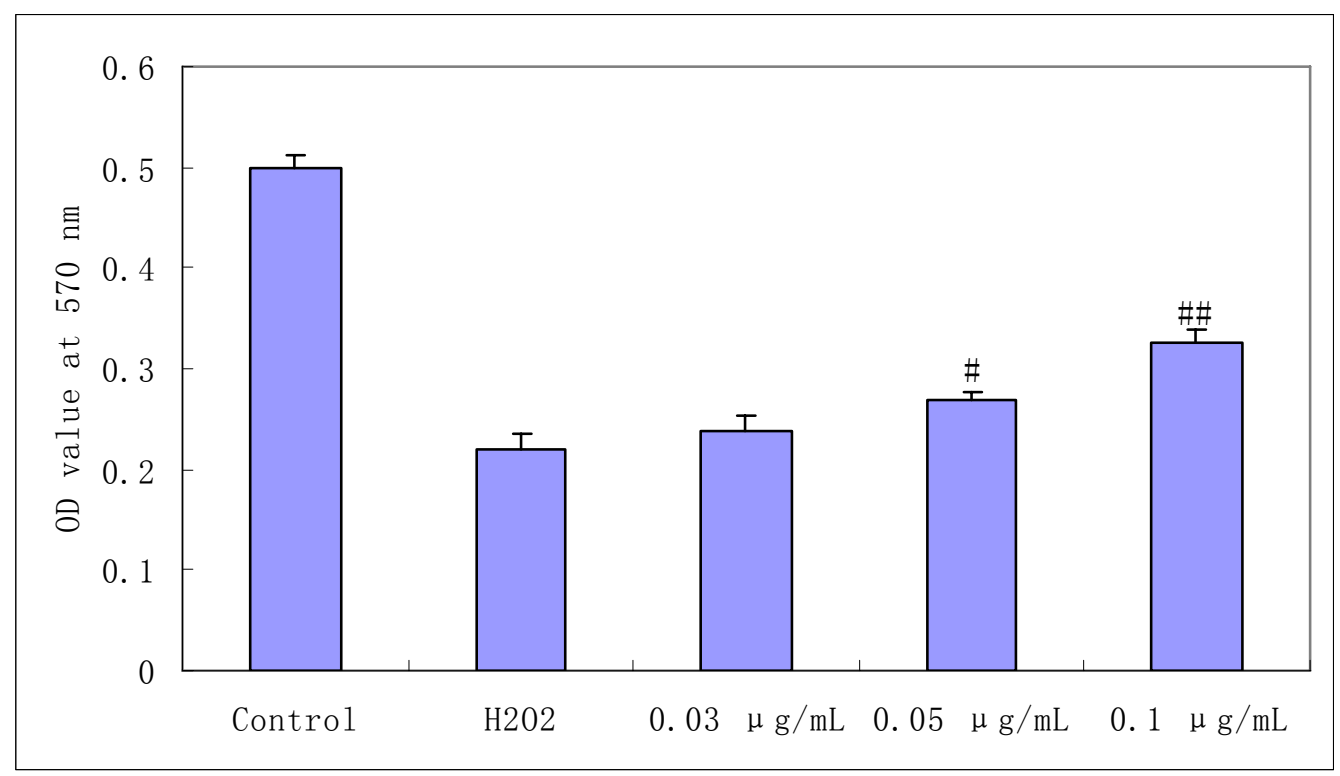

Figure 3. Salidroside inhibited $\mathrm{H}_{2} \mathrm{O}_{2}$-induced $\left[\mathrm{Ca}^{2+}\right] \mathrm{i}$ elevation (Recorded by inverted fluorescence microscope, Motic AE31 200×). (a). Control; (b). $\mathrm{H}_{2} \mathrm{O}_{2}$; (c). $0.03 \mu \mathrm{g} / \mathrm{mL}$ salidroside $+\mathrm{H}_{2} \mathrm{O}_{2} ;$ (d). $0.05 \mu \mathrm{g} / \mathrm{mL}$ salidroside $+\mathrm{H}_{2} \mathrm{O}_{2} ;$ (e). $0.1 \mu \mathrm{g} / \mathrm{mL}$ salidroside $+\mathrm{H}_{2} \mathrm{O}_{2}$; (f). Statistical analysis of fluorescence intensity data with Motic Advanced Images 3.2 software (China). Cells were treated with salidroside followed by $\mathrm{H}_{2} \mathrm{O}_{2}$ as described in 2.2. and $\left[\mathrm{Ca}^{2+}\right] \mathrm{i}$ levels were determined with Fluo-3/AM fluorescent dye.

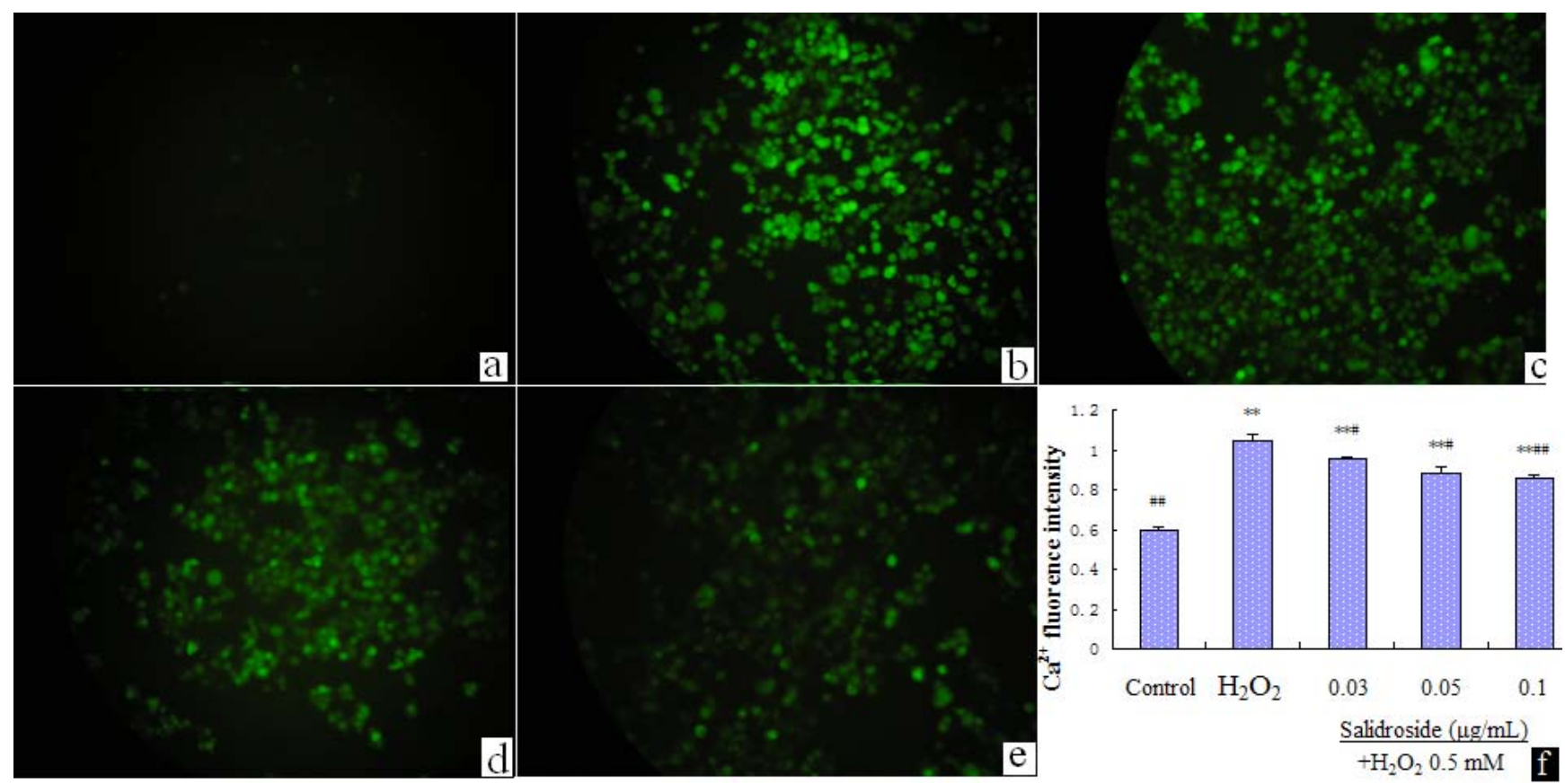




\subsection{Effects of Salidroside on the Formation of cAMP and cGMP}

We investigated the effects of salidroside on the level of cAMP/cGMP. As shown in Figure 4, $\mathrm{H}_{2} \mathrm{O}_{2}$ decreased the levels of cAMP (Figure 4a) and cGMP (Figure 4b) in HL-7702 cells. The decreased level of cAMP was restored by treatment with salidroside, while the decreased level of cGMP was not changed. It showed that salidroside exerts antioxidant effects by cAMP, not cGMP. Data are expressed as absorbance density (OD) and presented as mean \pm S.D. $(\mathrm{n}=4)$. ${ }^{*} \mathrm{p}<0.05$ and $* * \mathrm{p}<0.01$ compared with Control; \# $\mathrm{p}<0.05$ and \#\# $\mathrm{p}<0.01$ compared with $\mathrm{H}_{2} \mathrm{O}_{2}$ group.

Figure 4. (a). Effect of salidroside on cAMP level in cells; (b). Effect of salidroside on cGMP level in cells. Cells were treated with salidroside followed by $\mathrm{H}_{2} \mathrm{O}_{2}$ as described in 2.2. Contents of cAMP and cGMP were measured using human cyclic adenosine monophosphate Elisa kits and human cyclic guanosine monophosphate Elisa kits respectively.
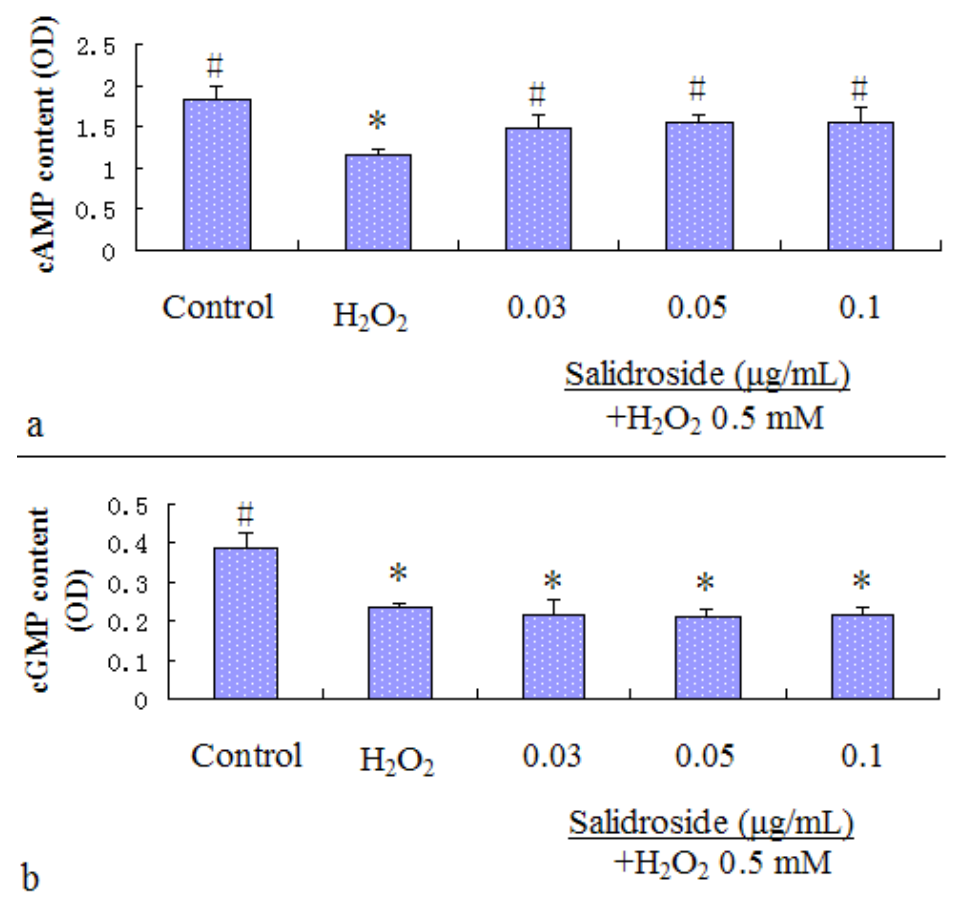

\subsection{Salidroside Inhibited $\mathrm{H}_{2} \mathrm{O}_{2}$-Induced ROS Elevation}

We examined the effect of salidroside on intracellular ROS. We found that incubating with $\mathrm{H}_{2} \mathrm{O}_{2}$ $(0.5 \mathrm{mM})$ for $100 \mathrm{~min}$ induced ROS elevation significantly, while pre-incubation with salidroside dose dependently suppressed the elevation of ROS (Figure 5). Statistical analysis of fluorescence intensity data with Motic Advanced Images 3.2 software. Data were expressed as mean \pm S.D. $(n=4)$. $* \mathrm{p}<0.05$ and $* * \mathrm{p}<0.01$ compared with Control; $\# \mathrm{p}<0.05$ and \#\# $\mathrm{p}<0.01$ compared with $\mathrm{H}_{2} \mathrm{O}_{2}$ group. 
Figure 5. Salidroside inhibited $\mathrm{H}_{2} \mathrm{O}_{2}$-induced $\mathrm{ROS}$ elevation (Recorded by inverted fluorescence microscope, Motic AE31 200×). (a). Control; (b). $\mathrm{H}_{2} \mathrm{O}_{2} ;$ (c). $0.03 \mu \mathrm{g} / \mathrm{mL}$ salidroside $+\mathrm{H}_{2} \mathrm{O}_{2} ;$ (d). $0.05 \mu \mathrm{g} / \mathrm{mL}$ salidroside $+\mathrm{H}_{2} \mathrm{O}_{2} ;$ (e). $0.1 \mu \mathrm{g} / \mathrm{mL}$ salidroside $+\mathrm{H}_{2} \mathrm{O}_{2}$; (f). Statistical analysis of fluorescence intensity data with Motic Advanced Images 3.2 software. Cells were treated with salidroside followed by $\mathrm{H}_{2} \mathrm{O}_{2}$ as described in 2.2.

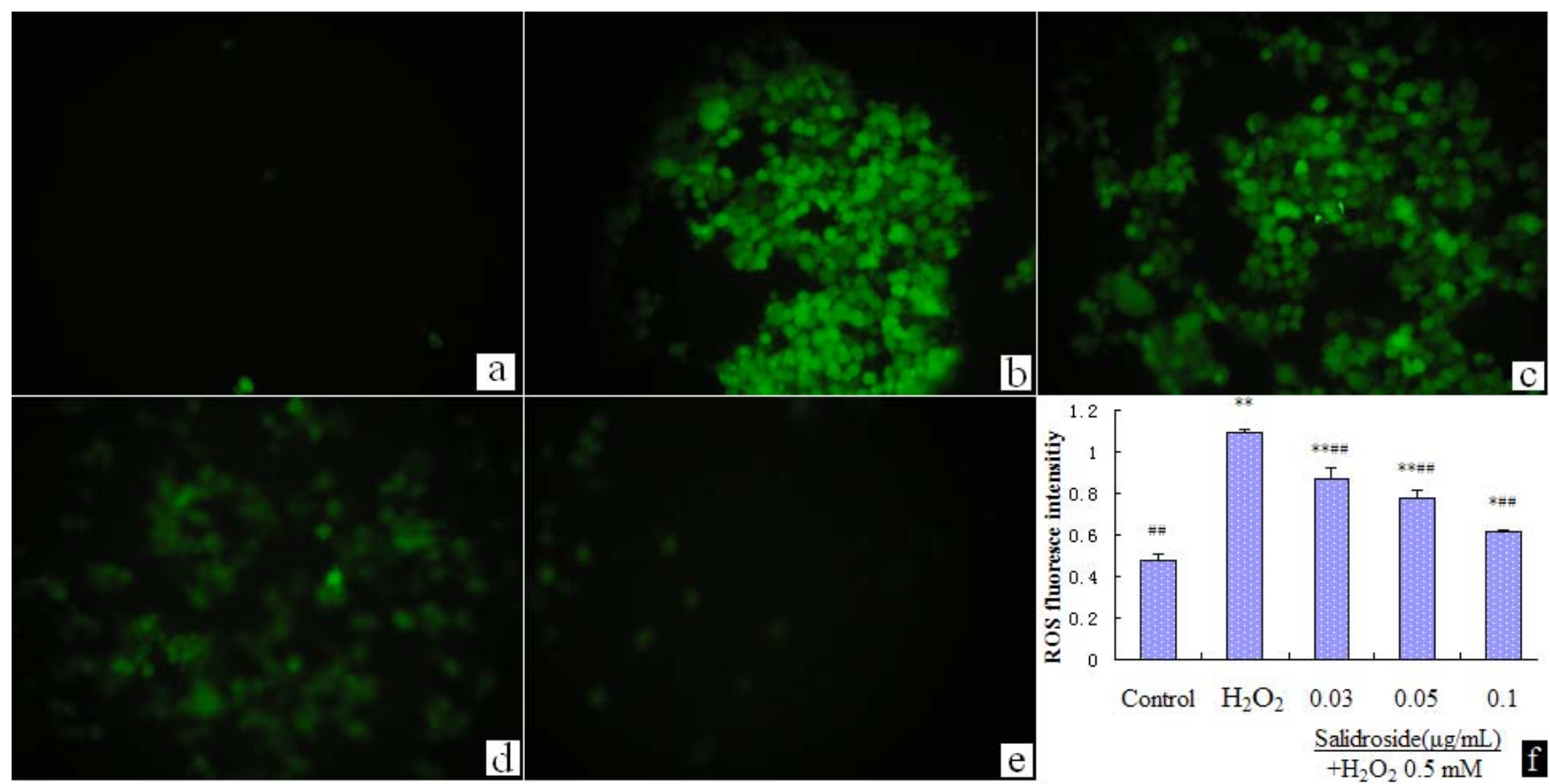

\subsection{Discussion}

Today, oxidative damages caused by ROS and oxidative stress play important roles in many diseases, such as endocrine disruption [18] $\mathrm{H}_{2} \mathrm{O}_{2}$, a major source of ROS, has been used in many studies to trigger oxidative damage [19]. In order to further studying antioxidant mechanism of salidroside, we investigated the effects of salidroside on $\mathrm{H}_{2} \mathrm{O}_{2}$-induced oxidative damage, cAMP, cGMP; $\left[\mathrm{Ca}^{2+}\right] \mathrm{i}$ and ROS level in HL-7702 cells.

In this paper, we used $\mathrm{H}_{2} \mathrm{O}_{2} 0.5 \mathrm{mM}$ to trigger oxidative damage in HL-7702 cells. Incubating with $\mathrm{H}_{2} \mathrm{O}_{2}$ for 100 min induced significant cell damage. Salidroside $(0.03,0.05,0.1 \mu \mathrm{g} / \mathrm{mL})$ could attenuate $\mathrm{H}_{2} \mathrm{O}_{2}$-induced damage in a dose-dependent manner. It is suggested that salidroside at dose of 0.03 , $0.05,0.1 \mu \mathrm{g} / \mathrm{mL}$ could efficiently protect cells from oxidative damage.

There is a mutual relationship between calcium and ROS signaling, which affects the local $\mathrm{Ca}^{2+}$ homeostasis [20]. $\mathrm{H}_{2} \mathrm{O}_{2}$ induced an $\left[\mathrm{Ca}^{2+}\right] \mathrm{i}$ rise which could still be evoked upon $\left[\mathrm{Ca}^{2+}\right] \mathrm{i}$ withdrawal and mitochondrial uncoupling [21]. In our research, $0.5 \mathrm{mM} \mathrm{H}_{2} \mathrm{O}_{2}$ successfully increased the level of $\left[\mathrm{Ca}^{2+}\right] \mathrm{i}$ in HL-7702 cells. $\left[\mathrm{Ca}^{2+}\right] \mathrm{i}$ levels are critical to cell life and changes in $\left[\mathrm{Ca}^{2+}\right] \mathrm{i}$ will affect matrix synthesis, as well as other functions [22]. In this experiment, salidroside inhibited $\mathrm{H}_{2} \mathrm{O}_{2}$-induced $\left[\mathrm{Ca}^{2+}\right] \mathrm{i}$ and ROS level and might be used in $\mathrm{Ca}^{2+}$ overloading disease.

cAMP is one of the most important second messengers in regulating a wide variety of cellular events and processes, such as metabolism, gene expression, cell division, migration, exocytosis and secretion. In non-excitable cells the fluctuations of $\left[\mathrm{Ca}^{2+}\right] \mathrm{i}$ and $[\mathrm{cAMP}] \mathrm{i}$ are often interrelated and 
linked via adenylate cyclase or phosphodiesterase [23]. Elevation of the cAMP level will decrease the $\left[\mathrm{Ca}^{2+}\right] \mathrm{i}$, and our result is consistent with this. The increased level of cAMP participates in activating PKA and consequently this enzyme phosphorylates its substrate proteins. Thus, the increased level of cAMP is linked to the activation of PKA [24]. Salidroside influenced $\mathrm{H}_{2} \mathrm{O}_{2}$-induced cAMP level, so it might be linked PKA-mediated phosphorylation.

cGMP is an important secondary messenger synthesized by the guanylyl cyclases and is also included in many cellular events and processes. It is believed that cGMP is produced via the activation of guanylate cyclase in the presence or absence of NO. NO is produced by the activation of NOS and affect the formation of cGMP. cGMP could affect $\left[\mathrm{Ca}^{2+}\right]_{\mathrm{i}}$ through direct inhibition of L-type $\mathrm{Ca}^{2+}$ channels [15]. cAMP and cGMP both are regulators of NO [25]. Salidroside couldn't influence cGMP level, so the change of NO may be mediated via cAMP-depend pathway.

In the experiment, we found that salidroside attenuated $\mathrm{H}_{2} \mathrm{O}_{2}$-induced cell damage, inhibited $\mathrm{H}_{2} \mathrm{O}_{2}$-induced $\left[\mathrm{Ca}^{2+}\right] \mathrm{i}$ elevation, scavenged ROS at low dose through cAMP-dependent pathway. These findings suggested that antioxidant protection of salidroside was associated with the cAMP-dependent pathway and decrease of $\left[\mathrm{Ca}^{2+}\right] \mathrm{i}$ and ROS levels.

\section{Experimental}

\subsection{Materials}

Salidroside (standard material, purity $>98 \%$ ) was purchased from the National Institute for the Control of Pharmaceutical and Biological Products. 3-[4,5-Dimethyl-2-thiazolyl]-2,5-diphenyl-2tetrazolium bromide (MTT) was purchased from Sigma (USA). Fluo-3/AM was obtained from Dojin Laboratories (Japan). 5-(and-6)-Chloromethyl-2',7'-dichlorodihydrofluorescein diacetate, acetyl ester (CM- $\mathrm{H}_{2}$ DCFDA) was obtained from Invitrogen (Molecular Probe), USA. RPMI 1640 was obtained from Gibco (USA). Human cyclic guanosine monophosphate ELISA kit and Human cyclic adenosine monophosphate ELISA kit were obtained from Blue Gene (Shanghai, China). FBS was obtained from Hangzhou (China). All other reagents were from commercial suppliers and of standard biochemical quality.

\subsection{Protective Effect of Salidroside on $\mathrm{H}_{2} \mathrm{O}_{2}$-Induced Cell Damage}

The human hepatocyte HL-7702 was obtained from SGST (China). The protective effect of salidroside was assessed by the MTT assay. Briefly, cells seeded on 96-well culture plates at $5 \times 10^{4} /$ well were incubated with salidroside for $24 \mathrm{~h}$. Following exposure to $\mathrm{H}_{2} \mathrm{O}_{2}(0.5 \mathrm{mM})$ for $100 \mathrm{~min}$, the MTT solution $(10 \mu \mathrm{L}, 5 \mathrm{mg} / \mathrm{mL})$ was added into each well and made the final concentration $0.5 \mathrm{mg} / \mathrm{mL}$, and then the plates were incubated for an additional $2 \mathrm{~h}$. After the medium was removed, DMSO $(100 \mu \mathrm{L})$ was added into each well before reading the microplates at $570 \mathrm{~nm}$. Cell viability was expressed as absorbance density (OD). 


\subsection{Determination of $\left[\mathrm{Ca}^{2+}\right] i$}

The $\left[\mathrm{Ca}^{2+}\right] \mathrm{i}$ was determined using Fluo-3/acetoxymethyl ester (Fluo-3/AM), described previously with slight modification [26]. Briefly, cells were loaded for $20 \mathrm{~min}$ at $37{ }^{\circ} \mathrm{C}$ with $20 \mu \mathrm{M}$ Fluo-3/AM containing $1 \mu \mathrm{M}$ pluronic acid F-127 for proper dispersal and $0.25 \mathrm{mM}$ sulfinpyrazone, to inhibit the leakage of the Fluo-3 dye. Shortly before use, a sample of loaded cells was washed with Krebs-RingerHepes (KRH) buffer (130 mM NaCl, $1.3 \mathrm{mM} \mathrm{KCl}, 2.2 \mathrm{mM} \mathrm{CaCl}_{2}, 1.2 \mathrm{mM} \mathrm{MgSO}$, $1.2 \mathrm{mM} \mathrm{KH}_{2} \mathrm{PO}_{4}$, $10 \mathrm{mM}$ Hepes, $10 \mathrm{mM}$ glucose, $\mathrm{pH}$ 7.4), to remove nonhydrolyzed Fluo-3/AM. Fluorescence measurements were performed using an inverted fluorescence microscope (Motic AE31invert, Xiamen, China).

\subsection{Measurement of cAMP and cGMP}

Cells $\left(5 \times 10^{4} / \mathrm{mL}\right)$ were pre-incubated with various concentrations of salidroside for $48 \mathrm{~h}$ at $37^{\circ} \mathrm{C}$ in 24-well culture plates, then incubated with $\mathrm{H}_{2} \mathrm{O}_{2}$ for 100 min. cAMP and cGMP were measured using the ELISA kits according to the manufacturer's instructions. The levels of cAMP and cGMP were expressed by absorbance density (OD).

\subsection{Measurement of ROS}

The intracellular ROS levels of cells were determined using CM-H2DCFDA assay [26]. For these experiments, cells were incubated with phosphate-buffered saline (PBS) and $5 \mathrm{mM} \mathrm{CM-H2DCFDA.}$ As a control, cells were incubated with PBS only. As a positive control, cells were incubated with PBS, $5 \mathrm{mM} \mathrm{CM-H2DCFDA,} \mathrm{and} 0.5 \mathrm{mM} \mathrm{H}_{2} \mathrm{O}_{2}$. After a 100 min incubation period with $0.5 \mathrm{mM} \mathrm{H}_{2} \mathrm{O}_{2}$, cells were trypsinized, washed, and resuspended in PBS. The levels of fluorescence intensity were immediately detected using an inverted fluorescent microscope (Motic AE31invert, Xiamen, China).

\subsection{Statistical Analysis}

All data were shown as means \pm S.D. (standard deviation of the mean) Statistical analyses were performed using Student's $t$-test and one-way analysis of variance (ANOVA). $\mathrm{p}<0.05$ was considered as statistically significant.

\section{Conclusions}

The data reported here firstly suggested that the antioxidant effects of salidroside were associated with down-regulation of $\left[\mathrm{Ca}^{2+}\right] \mathrm{i}$, ROS and at least partly via cAMP-dependent pathway.

\section{Acknowledgements}

This study was financed by the Chinese postdoctoral station of Jilin University (Number 801091800604). 


\section{References and Notes}

1. Ma, C.Y.; Tang, J.; Wang, H.X.; Tao, G.J.; Gu, X.H.; Hu, L. Preparative purification of salidroside from Rhodiola rosea by two-step adsorption chromatography on resins. J. Sep. Sci. 2009, 32, 185-191.

2. Mao, G.X.; Deng, H.B.; Yuan, L.G.; Li, D.D.; Li, Y.Y.Y.; Wang, Z. Protective role of salidroside against aging in a mouse model induced by D-galactose. Biomed. Environ. Sci. 2010, 23, 161-166.

3. Hu, X.L.; Zhang, X.Q.; Qiu, S.F.; Yu, D.H.; Lin, S.X. Salidroside induces cell-cycle arrest and apoptosis in human breast cancer cells. Biochem. Biophys. Res. Commun. 2010, 398, 62-67.

4. Skopinska-Rozewska, E.; Malinowski, M.; Wasiutynski, A.; Sommer, E.; Furmanowa, M.; Mazurkiewicz, M.; Siwicki, A.K. The influence of Rhodiola quadrifida 50\% hydro-alcoholic extract and salidroside on tumor-induced angiogenesis in mice. Pol. J. Vet. Sci. 2008, 11, 97-104.

5. Li, M.H.; Zhang, G.Z.; Wang, Y.S. Effect of salidroside on salivary adenoid cystic carcinoma cells in vitro. Hua Xi Kou Qiang Yi Xue Za Zhi 2008, 26, 312-315, 319.

6. Zhu, J.B.; Wan, X.Y.; Zhu, Y.P.; Ma, X.L.; Zheng, Y.W.; Zhang, T.B. Evaluation of salidroside in vitro and in vivo genotoxicity. Drug Chem. Toxicol. 2010, 33, 220-222.

7. Wang, H.B.; Ding, Y.Y.; Zhou, J.; Sun, X.L.; Wang, S.W. The in vitro and in vivo antiviral effects of salidroside from Rhodiola rosea L. against coxsackievirus B3. Phytomedicine 2009, 16, 146-155.

8. Zuo, G.Y.; Li, Z.Q.; Chen, L.R.; Xu, X.J. Activity of compounds from Chinese herbal medicine Rhodiola kirilowii (Regel) Maxim against HCVNS3 serine protease. Antivir. Res. 2007, 76, 86-92.

9. Wu, Y.L.; Piao, D.M.; Han, X.H.; Nan, J.X. Protective effects of salidroside against acetaminophen -induced toxicity in mice. Biol. Pharm. Bull. 2008, 31, 1523-1529.

10. Zou, Y.Q.; Cai, Z.Y.; Mao, Y.F.; Li, J.B.; Deng, X.M. Effects of salidroside-pretreatment on neuroethology of rats after global cerebral ischemia-reperfusion. Zhong Xi Yi Jie He Xue Bao 2009, 7, 130-134.

11. Yu, S.; Liu, M.; Gu, X.; Ding, F. Neuroprotective effects of salidroside in the pc12 cell model exposed to hypoglycemia and serum limitation. Cell. Mol. Neurobiol. 2008, 28, 1067-1078.

12. Liang, X.Q.; Xie, P.; Zhang, Y.; Shi, T.; Wang, Q.J.; Yan, T.H. Effects of salidroside on myocardial ischemia/reperfusion injury in rats. Chin. J. Nat. Med. 2010, 8, 127-131.

13. Wu, T.J.; Zhou, H.P.; Jin, Z.X.; Bi, S.H.; Yang, X.L.; Yi, D.H.; Liu, W.Y. Cardioprotection of salidroside from ischemia/reperfusion injury by increasing $\mathrm{N}$-acetylglucosamine linkage to cellular proteins. Eur. J. Pharmacol. 2009, 613, 93-99.

14. Li, H.B.; Ge, Y.K.; Zheng, X.X.; Zhang, L. Salidroside stimulated glucose uptake in skeletal muscle cells by activating AMP-activated protein kinase. Eur. J. Pharmacol. 2008, 588, 165-169.

15. Zhang, Q.H.; Lazar, M.; Molino, B.; Rodriguez, R.; Davidov, T.; Su, J.; Tse, J.; Weiss, H.R.; Scholz, P.M. Reduction in interaction between cGMP and cAMP in dog ventricular myocytes with hypertrophic failure. Amer. J. Physiol.-Heart Circ. Phy. 2005, 289, H1251-H1257.

16. Zhang, Li.; Yu, H.; Zhao, X.; Lin, X.; Tan, C.; Cao, G.; Wang, Z. Neuroprotective effects of salidroside against beta-amyloid-induced oxidative stress in SH-SY5Y human neuroblastoma cells. Neurochem. Int. 2010, 57, 547-555. 
17. Kim, J.I.; Kim, H.H.; Kim, S.; Lee, K.T.; Ham, I.H.; Whang, W.K. Antioxidant compounds from quercus salicina blume stem. Arch. Pharm. Res. 2008, 31, 274-278.

18. Monroe, R.K.; Halvorsen, S.W. Environmental toxicants inhibit neuronal Jak tyrosine kinase by mitochondrial disruption. Neurotoxicology 2009, 30, 589-598.

19. Cai, L.; Wang, H.; Li, Q.; Qian, Y.F.; Yao, W.B. Salidroside inhibits $\mathrm{H}_{2} \mathrm{O}_{2}$-induced apoptosis in PC12 cells by preventing cytochrome c release and inactivating of caspase cascade. Acta Biochim. Biophys. Sinica 2008, 40, 796-802.

20. Csordas, G.; Hajnoczky, G. SR/ER-mitochondrial local communication: Calcium and ROS. Biochim. Biophys. Acta 2009, 1787, 1352-1362.

21. Gerich, F.J.; Funke, F.; Hildebrandt, B.; Fasshauer, M.; Muller, M. $\mathrm{H}_{2} \mathrm{O}_{2}$-mediated modulation of cytosolic signaling and organelle function in rat hippocampus. Pflugers Arch.-Eur. J. Phys. 2009, 458, 937-952.

22. White, R.; Gibson, J.S. The effect of oxygen tension on calcium homeostasis in bovine articular chondrocytes. J. Orthop. Surg. Res. 2010, 5, 27.

23. Mironov, S.L.; Skorova, E.; Taschenberger, G.; Hartelt, N.; Nikolaev, V.O.; Lohse, M.J.; Kugler, S. Imaging cytoplasmic cAMP in mouse brainstem neurons. BMC Neurosci. 2009, 10, 29.

24. Cho, H.J.; Cho, J.Y.; Rhee, M.H.; Park, H.J. Cordycepin (3'-deoxyadenosine) inhibits human platelet aggregation in a cyclic AMP- and cyclic GMP-dependent manner. Eur. J. Pharmacol. 2007, 558, 43-51.

25. Hemmrich, K.; Gummersbach, C.; Paul, N.E.; Goy, D.; Suschek, C.V.; Kroncke, K.D.; Pallua, N. Nitric oxide and downstream second messenger cGMP and cAMP enhance adipogenesis in primary human preadipocytes. Cytotherapy 2010, 12, 547-553.

26. Yamashiro, K.; Sasano, T.; Tojo, K.; Namekata, I.; Kurokawa, J.; Sawada, N.; Suganami, T.; Kamei, Y.; Tanaka, H.; Tajima, N.; et al. Role of transient receptor potential vanilloid 2 in LPSinduced cytokine production in macrophages. Biochem. Biophs. Res. Commun. 2010, 398, 284-289.

Sample Availability: Samples of the salidroside are available from the authors.

(C) 2011 by the authors; licensee MDPI, Basel, Switzerland. This article is an open access article distributed under the terms and conditions of the Creative Commons Attribution license (http://creativecommons.org/licenses/by/3.0/). 